Revue d'histoire de l'Amérique française

REVUE D.HISTOIRE DE L'AMÉRIQUE FRANÇAISE

\title{
L'histoire culturelle comme domaine historiographique au Québec
}

\section{Yvan Lamonde}

Volume 51, numéro 2, automne 1997

Les pratiques de l'histoire de l'Amérique française depuis 50 ans

URI : https://id.erudit.org/iderudit/305650ar

DOI : https://doi.org/10.7202/305650ar

Aller au sommaire du numéro

Éditeur(s)

Institut d'histoire de l'Amérique française

ISSN

0035-2357 (imprimé)

1492-1383 (numérique)

Découvrir la revue

Citer cet article

Lamonde, Y. (1997). L'histoire culturelle comme domaine historiographique au Québec. Revue d'histoire de l'Amérique française, 51(2), 285-299.

https://doi.org/10.7202/305650ar
Résumé de l'article

Cet article analyse le mode de constitution de l'histoire culturelle au Québec comme domaine historiographique en montrant comment s'est conceptualisée cette appellation et comment elle a développé des outils méthodologiques. L'étude explore les relations entre l'histoire culturelle et d'autres domaines de l'historiographie (histoire de la littérature, de la religion, de la politique, des arts et l'ethnologie) ainsi que ses rapports à des questions débattues de

l'historiographie ( "révisionnisme », libéralisme, fascisme). L'article situe enfin l'histoire culturelle pratiquée au Québec dans l'historiographie internationale.
Tous droits réservés @ Institut d'histoire de l'Amérique française, 1997
Ce document est protégé par la loi sur le droit d'auteur. L'utilisation des services d’Érudit (y compris la reproduction) est assujettie à sa politique d'utilisation que vous pouvez consulter en ligne.

https://apropos.erudit.org/fr/usagers/politique-dutilisation/ 


\title{
L'HISTOIRE CULTURELLE COMME DOMAINE HISTORIOGRAPHIQUE AU QUÉBEC
}

\author{
YVAN LAMONDE \\ Département de langue et littérature françaises \\ Université McGill*
}

\begin{abstract}
RÉSUMÉ
Cet article analyse le mode de constitution de l'histoire culturelle au Québec comme domaine historiographique en montrant comment s'est conceptualisée cette appellation et comment elle a développé des outils méthodologiques. L'étude explore les relations entre l'histoire culturelle et d'autres domaines de l'historiographie (histoire de la littérature, de la religion, de la politique, des arts et l'ethnologie) ainsi que ses rapports à des questions débattues de l'historiographie («révisionnisme», libéralisme, fascisme). L'article situe enfin l'histoire culturelle pratiquée au Québec dans l'historiographie internationale.
\end{abstract}

\section{ABSTRACT}

The following article analyses how Quebec cultural history came to constitute a domain of historiography, how it is conceptualized and what its methodological concerns are. This study also explores the relations of cultural history to other historical fields (literature, religion, politics, art, ethnology) and its position with regard to current issues ( «revisionism», liberalism, fascism). The article concludes by situating Quebec cultural history within international historiography.

L'histoire socioculturelle a aujourd'hui conquis sa place dans la recherche historique internationale après que celle-ci eut privilégié l'histoire économique et l'histoire sociale dans toutes ses variantes'

* $\quad$ Pour leurs commentaires sur ce texte, l'auteur remercie Jean-Paul Bernard, Gérard Bouchard, Fernande Roy, Ronald Rudin et Pierre Savard.

1. Parmi les bilans internationaux, Jean-Pierre Rioux et Jean-François Sirinelli, dir., Pour une histoire culturelle (Paris, Seuil, 1997), 455 p.; Roger Chartier, «Histoire culturelle et histoire des mentalités. Trajectoires et questions», Revue de synthèse, 111-112 (1983): 277-307, publié en anglais dans Dominick LaCapra et Steven L. Kaplan, dir., Modern European Intellectual History. Reappraisals and New Perspectives (Ithaca, Cornell University Press, 1982), 13-46; John Higham et Paul K. Conkin, dir., New Directions in American Intellectual History (Baltimore, Johns Hopkins University Press, 1979), 245 p.; Robert Darnton, «Intellectual and Cultural History», dans Michael Kammen, dir., The Past Before Us. Contemporary Historical Writing in the United States (Ithaca, Cornell University Press, 1980), 327-354. 
Pour des raisons de division du travail et de mandats confiés à divers auteurs par les organisateurs du colloque soulignant le cinquantenaire de la Revue d'histoire de l'Amérique française [RHAF], nous laissons à d'autres collègues le traitement de l'histoire religieuse, de l'histoire des sciences, de l'histoire des Amérindiens, de l'histoire des femmes, de l'histoire des travailleurs et de l'histoire de la Nouvelle-France. Ces exclusions - circonstancielles - ne nous libèrent pas pour autant d'une définition du domaine couvert ici. La définition du domaine de l'histoire culturelle est soit générale et impérialiste, soit spécifique et paraissant du coup trop exclusive. Les définitions de ce champ historiographique peuvent se résumer ainsi: l'histoire culturelle est l'étude de l'évolution des idées, des sentiments, des croyances, des pratiques et des représentations. C'est ce que nous entendons faire, tout en privilégiant une approche où la recherche a en quelque sorte, depuis une trentaine d'années, défini son champ en le construisant. $\mathrm{Ce}$ suivi des phases de la recherche en histoire culturelle, de l'évolution de ses objets et de ses méthodes ne permet toutefois pas de tout couvrir. Pour des raisons de compétence et d'espace, nous ne disons rien ici de la culture populaire, rurale ou urbaine, sachant pertinemment certains de nos travaux ont exploré ces avenues - que c'est là la culture de la majorité de la population et que sa négligence ne peut être excusée que par des limites d'espace.

De la fondation de la $R H A F$ en 1947 à la fin de la décennie 1950, au moment où la nouvelle génération d'historiens (Ouellet, Hamelin, Galarneau, Brunet, Frégault) commence à publier, l'histoire culturelle n'est pas encore une «appellation contrôlée», mais un certain nombre d'articles dans la $R H A F$ peuvent annoncer des cépages qui produiront dans les années à venir. La revue privilégie les articles sur la Nouvelle-France et sur quelques grandes familles qui s'y sont illustrées, mais une certaine histoire religieuse, greffée à des courants d'idées, préfigure des orientations de l'histoire culturelle: articles sur le gaumisme (classiques chrétiens ou païens dans l'enseignement), sur la polémique des abbés Ferland et Brasseur de Bourbourg, sur l'interdit du dominicain Gonthier. Le frère Robert Sylvain, plus tard connu sous le nom de Philippe Sylvain, y publie des articles sur Lamartine au Canada français. Une certaine histoire politique, pratiquée par l'abbé Lionel Groulx ou par le jésuite Léon Pouliot, s'alimente au terreau des idées et des préoccupations culturelles et donne des contributions sur les évêques et le projet d'Union, sur la crise politique de 1848-1849. Groulx publie abondamment sur Papineau (ses relations avec les Irlandais, son fils Lactance) et sur les patriotes et leur «britannisme». Il n'est pas le seul à s'intéresser aux rébellions: Victor Morin publie un 
article sur «la république de 1838», Robert-Lionel Séguin sur le patriote Luc-Hyacinthe Masson. Michel Brunet explore déjà les réactions des Canadiens à 1760 et à 1789; Guy Frégault s'intéresse à la «civilisation canadienne» durant la guerre de Sept Ans et Claude Galarneau propose un cru culturel dans «Jeunesse de Clio ou la recherche en histoire», communication présentée à la "réunion générale» de l'Institut d'histoire de l'Amérique française d'avril 1955 et nourrie ça et là de références à Lucien Febvre, Marc Bloch, Ernest Labrousse et Charles Morazé ${ }^{2}$.

L'histoire culturelle s'est certes constituée au Québec comme domaine de l'historiographie par la recherche et l'enseignement (Galarneau, Ouellet, Sylvain, Bernard, Savard, Eid), mais de façon particulière, elle fut esquissée et mise au point par des suivis bibliographiques et par des bilans successifs qui, par effet cumulatif, ont fait voir la logique de développement et la cohérence recherchée des tra$v^{\text {vaux }}{ }^{3}$. En ce sens, on peut avancer qu'à l'intérieur même d'une dynamique de spécialisation du domaine, s'est manifesté un effort constant de conceptualisation, de totalisation qui nous semble avoir contré un effet de fragmentation ou de dispersion, caractéristique de la période antérieure. Cet effort n'a pourtant pas donné lieu à une conceptualisation satisfaisante de l'histoire culturelle au sens où nous disposerions d'un organigramme où l'histoire de la culture bourgeoise et savante serait bien arrimée à la culture populaire rurale et urbaine et où les formes d'expression (le livre, la peinture, le sermon, la grève

2. Thomas Charland, «Un gaumiste canadien: l'abbé Alexis Pelletier», Revue d' histoire de l'Amérique française [RHAF], 1,2 (septembre 1947): 195-236 et 1,3 (décembre 1947): 463468; id., «L'affaire Brasseur de Bourbourg», 2,2 (juin 1948): 250-274; id., "Les débuts du père Gonthier dans la polémique», 6,2 (septembre 1952): 234-246; id., "L'interdit du père Gonthier», 8,1 (juin 1954): 72-96; Robert Sylvain, «Lamartine et les catholiques de France et du Canada», 4,1 (juin 1950): 29-60, 4,2 (septembre 1950): 233-248 et 4,3 (décembre 1950): 375-397; Léon Pouliot, «Les évêques du Bas-Canada et le projet d'Union (1840)», 8,2 (septembre 1954): 157 170; Lionel Groulx, «Un débat parlementaire en 1849», 2,3 (décembre 1948): 375-389; id., «Papineau et le péril irlandais», 4,4 (mars 1951): 512-520; id., «Fils de grand homme», 10,3 (décembre 1956): 310-332; id., «Le "britannisme" des "Patriotes"», 5,3 (décembre 1951): 416425; Victor Morin, «La "république" de 1838», 22,4 (mars 1949): 483-512; Robert-Lionel Séguin, «Biographie d'un Patriote de '37: le Dr Luc Hyacinthe Masson», 3,3 (décembre 1949): 349-366; Michel Brunet, «Premières réactions des vaincus de 1760 devant leurs vainqueurs», 6,4 (mars 1953): 506-516; Guy Frégault, «La guerre de Sept ans et la Civilisation canadienne», 7,2 (septembre 1953): 183-206; Claude Galarneau, «Jeunesse de Clio ou la recherche en histoire», 9,1 (juin 1955): 3-13.

3. Pour les suivis bibliographiques et la référence aux travaux d'historiens de la culture, Yvan Lamonde, L'histoire des idées au Québec (1760-1960) (Montréal, Bibliothèque nationale du Québec, 1989), 167 p.; «L'histoire culturelle et intellectuelle du Québec (1960-1990): bibliographie des études», Littératures, 4 (1989): 155-189; «L'histoire des idées au Québec (17601993). Premier supplément bibliographique et tendances de la recherche (1re partie)», Cahiers

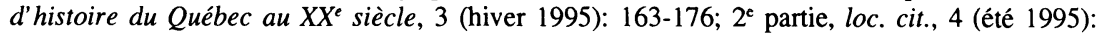
152-167. 
ouvrière, le conte, les motifs des moules pour le sucre d'érable) seraient également prises en compte. Ajoutons qu'en voulant sortir d'un vieil idéalisme où les idées circulaient dans la noosphère des considérations vagues, l'histoire culturelle s'est imposée, d'une part, de passer par la porte étroite de l'histoire économique, de la démographie et de l'histoire sociale et que, d'autre part, l'histoire intellectuelle ne pouvait être qu'une province d'une histoire culturelle plus générale parce que plus englobante socialement. Alors que l'histoire culturelle englobe tous les groupes sociaux et toutes leurs formes d'expression ou de langages - autant l'écrit, l'éloquence, l'oralité de la culture populaire, la gestuelle, la culture matérielle -, l'histoire intellectuelle privilégie l'écrit et une certaine expression verbale.

La mise à jour fréquente des travaux et des problématiques permet aujourd'hui d'identifier trois phases successives de la recherche ${ }^{4}$. Marcel Trudel, Claude Galarneau, Philippe Sylvain et Pierre Savard se sont d'abord intéressés aux «influences» culturelles européennes ou «métropolitaines» sur le Canada et le Québec ${ }^{5}$. Puis les historiens ont recentré la perspective culturelle ou intellectuelle sur la colonie et ce, en deux étapes: d'abord par des travaux de Fernand Ouellet, JeanPierre Wallot, John Hare, Philippe Sylvain, Jean-Paul Bernard, Jacques Monet et Nadia Fahmy-Eid ${ }^{6}$ sur les idées politiques qui circu-

4. Yvan Lamonde, «L'histoire culturelle et intellectuelle du Québec: tendances et aspects méthodologiques» et «La recherche sur l'histoire socioculturelle du Québec depuis 1970», dans Territoires de la culture québécoise (Sainte-Foy, Les Presses de l'Université Laval, 1991), 7-24, 25-48; Fernand Dumont et Fernand Harvey, «La recherche sur la culture», Recherches sociographiques, 26,1-2 (1985): 85-118; Pierre Trépanier, «Vie intellectuelle», dans Jacques Rouillard, dir., Guide d'histoire du Québec, du régime français à nos jours (Montréal, Éditions du Méridien, 1991), 277-291.

5. Marcel Trudel, L'influence de Voltaire au Canada (Montréal, Fides, 1945), 2 vol.; Claude Galarneau, La France devant l'opinion canadienne (1789-1815) (Québec/Paris, Les Presses de l'Université Laval/Armand Colin, 1970), xii-401 p., préface d'André Latreille; voir la bibliographie de P. Sylvain, dans Nive Voisine et Jean Hamelin, dir., Les ultramontains canadiens-français (Montréal, Boréal Express, 1985), 19-20; P. Savard, Jules-Paul Tardivel, la France et les États-Unis (1851-1905) (Québec, Les Presses de l'Université Laval, 1967), xxxvii$499 \mathrm{p}$.

6. Fernand Ouellet, Éléments d'histoire sociale du Bas-Canada (Montréal, Hurtubise HMH, 1972), 379 p.; Jean-Pierre Wallot, Un Québec qui bougeait. Trame socio-politique au tournant du XIX ${ }^{e}$ siècle (Trois-Rivières, Éditions du Boréal Express, 1973), 345 p.; John Hare, La pensée socio-politique au Québec (1764-1812). Analyse sémantique (Ottawa, Éditions de l'Université d'Ottawa, 1977), 103 p.; Philippe Sylvain, «Libéralisme et ultramontanisme au Canada français», dans W. L. Morton, dir., The Shield of Achilles/Le bouclier d'Achille (Toronto, McClelland and Stewart, 1968), 111-138, 220-255; Jean-Paul Bernard, Les Rouges. Libéralisme, nationalisme et anticléricalisme au milieu du XIX $X^{e}$ siècle (Montréal, Les Presses de l'Université du Québec, 1971), xx-394 p.; Jacques Monet, The Last Cannon Shot. A Study of FrenchCanadian Nationalism (Toronto, University of Toronto Press, 1969), x-422 p., traduit sous le titre La première Révolution tranquille; Nadia Fahmy-Eid, Le clergé et le pouvoir politique au Québec. Une analyse de l'idéologie ultramontaine au milieu du XIXe siècle (Montréal, Hurtubise HMH, 1978), $318 \mathrm{p}$. 
laient dans la colonie (libéralisme, nationalisme, anticléricalisme, ultramontanisme), travaux poursuivis bientôt à l'intérieur de la problématique des idéologies dans les séminaires codirigés par Fernand Dumont et Jean Hamelin ${ }^{7}$; ensuite, les recherches de Claude Galarneau, John Hare, Yvan Lamonde, Marcel Lajeunesse, Jean de Bonville et Allan Greer s'orientèrent vers l'analyse des formes culturelles coloniales (le collège, l'imprimé, la bibliothèque, la librairie, l'association, la presse, l'alphabétisation) à travers lesquelles circulaient les idées politiques et religieuses ${ }^{8}$. Marquée par l'histoire sociale (travaux de Ouellet sur la bourgeoisie libérale et de Lamonde sur la culture populaire urbaine ${ }^{9}$ ), l'histoire culturelle approfondit sa territorialité coloniale nord-américaine en scrutant les dimensions de la culture régionale grâce aux travaux de Normand Séguin et de Gérard Bouchard sur le Saguenay, de René Hardy et Jean Roy sur la Mauricie et grâce aux diverses recherches sur l'histoire des régions du Québec menées par l'Institut québécois de recherche sur la culture ${ }^{10}$. Deux problématiques sont sorties des travaux sur le Saguenay: celle de la désarticulation du pouvoir économique et du pouvoir socioculturel et celle des «collectivités neuves», c'est-à-dire des sociétés du Nouveau Monde formées par l'immigration et témoignant par divers indicateurs de leur appartenance continentale.

7. Voir la série Les idéologies au Canada français (1850-1900, 1900-1929, 1930-1939, 1940-1976) publiée aux Presses de l'Université Laval.

8. Claude Galarneau, Les collèges classiques au Canada français (1620-1970) (Montréal, Fides, 1978), 287 p.; John Hare et Jean-Pierre Wallot, «Les imprimés au Québec (1764 1820)», dans Yvan Lamonde, dir., L'imprimé au Québec. Aspects historiques (18e-20 siècle) (Québec, Institut québécois de recherche sur la culture, 1983), 79-125; Yvan Lamonde, Les bibliothèques de collectivités à Montréal (17e-19e siècle) (Montréal, Bibliothèque nationale du Québec, 1979), 139 p.; id., La librairie et l'édition à Montréal (1776-1920) (Montréal, Bibliothèque nationale du Québec, 1991), 198 p.; id., «Les associations au Bas-Canada: de nouveaux marchés aux idées (1840-1867)», Histoire sociale/Social History, 8,16 (novembre 1975): 361369; Marcel Lajeunesse, Les Sulpiciens et la vie culturelle à Montréal au XIXe siècle (Montréal, Fides, 1982), 280 p.; Jean de Bonville, La presse québécoise de 1884 à 1914. Genèse d'un média de masse (Québec, Les Presses de l'Université Laval, 1988), 416 p.; Allan Greer, «L'alphabétisation et son histoire au Québec: état de la question», dans Yvan Lamonde, dir., L'imprimé au Québec, op. cit., 25-51.

9. Fernand Ouellet, «Structure des occupations et ethnicité dans les villes de Québec et de Montréal (1819-1844)", Éléments d' histoire sociale, op. cit., 177-204; Yvan Lamonde, Lucia Ferretti et Daniel LeBlanc, La culture ouvrière à Montréal (1880-1920). Bilan historiographique (Québec, Institut québécois de recherche sur la culture, 1982), 176 p.; Yvan Lamonde et Raymond Montpetit, Le parc Sohmer de Montréal (1889-1919). Un lieu populaire de culture urbaine (Québec, Institut québécois de recherche sur la culture, 1986), 231 p.

10. Normand Séguin, La conquête du sol au XIXe siècle (Sillery, Éditions du Boréal Express, 1977), 295 p.; Gérard Bouchard, «Un essai d'anthropologie régionale: l'histoire sociale du Saguenay aux XIX ${ }^{\mathrm{e}}$ et XXe $\mathrm{XX}^{\mathrm{e}}$ siècles», Annales ESC, 34,1 (février 1979): 106-125; id., «Sur la dynamique culturelle des régions de peuplement», Canadian Historical Review, 68,4 (1986): 473-490; René Hardy et Jean Roy, «Encadrement social et mutation de la culture religieuse en Mauricie (1850-1900)», Questions de culture, 5 (1983): 61-78. 
Un autre indice de la constitution et de l'autonomisation de l'histoire culturelle réside dans ses préoccupations méthodologiques, c'està-dire dans la recherche de façons de faire spécifiques à ses objets. On a d'abord pris prétexte des suivis bibliographiques et de la nécessité de classement des entrées bibliographiques pour proposer non seulement une périodisation de l'évolution culturelle, mais aussi une certaine conceptualisation du territoire et du cadastre de ce domaine de l'historiographie $^{11}$. Les praticiens de l'histoire culturelle ont de plus cherché à quantifier, dans la mesure du possible, les phénomènes considérés. Empruntant à la démographie et aux travaux d'autres domaines de l'historiographie, ils précisent les types d'agglomérations étudiées, les incidences de l'immigration, les effectifs des professions $^{12}$ et, plus globalement, ils cherchent à établir un seuil au-delà duquel une église, une auberge, un bureau de poste, une école, un journal, une bibliothèque ou une association deviennent démographiquement, économiquement et socialement possibles. C'est dans le domaine de l'histoire de l'imprimé ${ }^{13}$ que la quantification s'est révélée la plus originale et la plus intense: nombre, types, formats d'imprimés dans une période donnée ${ }^{14}$; à l'initiative de Claude Galarneau, utilisation critique de l'inventaire après décès ${ }^{15}$ pour analyser les bibliothèques privées et la pénétration sociale du livre; dénombrement de registres d'emprunt de la bibliothèque de l'Institut canadien de Montréal ${ }^{16}$ pour scruter les emprunts et les emprunteurs; recours à la publicité des journaux et à la quantification pour mieux

11. Yvan Lamonde, L'histoire des idées au Québec (1760-1960), op. cit., 7-13.

12. Outre Fernand Ouellet déjà cité à la note 9, Louis-Edmond Hamelin, «Évolution numérique séculaire du clergé catholique dans le Québec», Recherches sociographiques, 2 (avril-juin 1961): 213-234; Serge Gagnon et Louise Lebel-Gagnon, «Le milieu d'origine du clergé québécois (1775-1840): mythes et réalités», RHAF, 37,3 (décembre 1983): 373-397.

13. Pour des suivis bibliographiques de l'histoire de l'imprimé faits en collaboration, Bibliographie des études québécoises sur l'imprimé (1970-1987) (Montréal, Bibliothèque nationale du Québec, 1991), 124 p.; Premier supplément (1988-1989) (Montréal, Bibliothèque nationale du Québec, 1993), 73 p.

14. Yvan Lamonde et Claude Beauchamp, Données statistiques sur l'histoire culturelle $d u$ Québec (1760-1900) (Chicoutimi, Institut interuniversitaire de recherches sur les populations, 1996), $146 \mathrm{p}$.

15. Y. Morin, «Les bibliothèques privées à Québec d'après les inventaires après décès (1800-1819)», dans Yvan Lamonde, L'imprimé au Québec, op. cit., 147-165; E. Langlois, Livres et lecteurs à Québec (1760-1799), mémoire de maîtrise (histoire), Université Laval, 1984, xvi112 p.; Gilles Labonté, Les bibliothèques privées à Québec (1820-1829), mémoire de maitrise (histoire), Université Laval, 1986, xxvi-301 p.

16. Louis-Georges Harvey et Mark V. Olsen, «La circulation de la bibliothèque de l'Institut canadien de Montréal (1865-1875)», Histoire sociale/Social History, 19,37 (mai 1986): 139-160; Yvan Lamonde, «La bibliothèque de l'Institut canadien de Montréal (1852-1876): pour une analyse multidimensionnelle» [1988], dans Yvan Lamonde, Territoires de la culture québécoise, op. cit., 117-147. 
connaître l'offre de livres faite par les marchands et libraires ${ }^{17}$; utilisation des signatures sur les actes de mariage pour établir des taux d'alphabétisation ${ }^{18}$. Ces efforts de quantification ont ainsi entraîné la constitution de séries statistiques et un esprit d'histoire sérielle dans le domaine de la culture, permettant du coup à l'histoire culturelle des énoncés valides sur des périodes à long ou moyen terme: propriétaires de livres à Québec entre 1760 et 1830, emprunts et emprunteurs de livres à l'Institut canadien de Montréal sur un quart de siècle, alphabétisation du Québec du XVII ${ }^{\mathrm{e}}$ au $\mathrm{XX}^{\mathrm{e}}$ siècle, contenu de la librairie Bossange entre 1816 et $1819^{19}$, sans parler des «pascalisants», de ceux qui «font leurs Pâques ${ }^{20}$ ».

La constitution de séries documentaires originales et, en particulier, en histoire du livre, l'usage des catalogues manuscrits et imprimés de bibliothèques et de librairies ont confronté les historiens au problème méthodologique de la classification des titres. Et pour en permettre l'étude comparative au-delà du XVIII' siècle, pour lequel le Catalogue de la Bibliothèque du Roi pouvait s'imposer, il a fallu construire et valider une classification universelle pour l'analyse et la comparaison internationale des bibliothèques et des librairies au XIX ${ }^{\mathrm{e}}$ siècle ${ }^{21}$.

Au fil des recherches sur les courants d'idées ou sur l'imprimé, il est apparu de plus en plus évident que la validation sociale des travaux en histoire culturelle passait par l'étude systémique, c'est-à-dire par l'analyse du circuit complet de la production, de la diffusion, de la consommation et de la réception d'un phénomène ou d'un objet culturel.

17. Réjean Lemoine, Le marché du livre à Québec (1764-1839), mémoire de maîtrise (histoire), Université Laval, 1981, 286 p.

18. Michel Verrette, «L'alphabétisation de la ville de Québec de 1750 à 1859», RHAF, 39,1 (été 1985): 51-76; id., L'alphabétisation au Québec (1660-1900), thèse de doctorat (histoire), Université Laval, 1989, xxxii-393 p.

19. Yvan Lamonde, «La librairie Hector Bossange de Montréal (1815-1819) et le commerce international du livre» [1988], dans Yvan Lamonde, Territoires de la culture québécoise, op. cit., 181-218.

20. Louis Rousseau, «La conduite pascale dans la région montréalaise (1831-1865): un indice des mouvements de la ferveur religieuse», dans L'Église de Montréal (1836-1936): aperçus d'hier et d'aujourd' hui (Montréal, Fides, 1986), 270-284.

21. Yvan Lamonde, "A Universal Classification for the Study of Nineteenth-Century Libraries and Booksellers», Libraries and Culture, 24,2 (printemps 1989): 158-197 et aperçus dans «Une classification pour l'étude des bibliothèques et de la librairie au XIX ${ }^{\mathrm{e}}$ siècle», Documentation et bibliothèques, 35,2 (avril-juin 1989): 53-58. 


\section{DES PONTS VERS D'AUTRES DOMAINES DE LA RECHERCHE HISTORIQUE}

Ce sont probablement les recherches sur l'histoire des «idéologies» et sur l'histoire de l'imprimé en particulier et l'approche systémique de celle-ci - de la production à la «réception» - qui ont permis un rapprochement avec l'histoire littéraire. On en prendra pour indice le collectif sous la responsabilité de Maurice Lemire, La vie littéraire au Québec, qui représente l'effort le plus significatif pour conjuguer textes et contextes. Les travaux de Jacques Michon sur l'édition littéraire, l'analyse du contenu littéraire de la bibliothèque de l'Institut canadien de Montréal ou l'enquête de Bernard Andrès sur l'archéologie du littéraire au Québec à la fin du XVIII e siècle confirment cet arrimage du culturel et du littéraire. Et si besoin était d'un dernier indice, on référerait au colloque Garneau qui a réuni en 1995 littéraires et historiens et qui a fait la preuve en parlant du regard différent et stimulant porté par chacun sur le texte, le contexte et l'écriture de l'histoire ${ }^{22}$.

Le territoire de l'histoire culturelle et celui de l'histoire religieuse ont trop en commun pour que ces deux domaines de recherche ne se soient fréquemment rencontrés ou superposés. Si Philippe Sylvain et Pierre Savard ont personnifié pendant près d'un quart de siècle cette symbiose du religieux et du culturel et la laïcisation de l'histoire religieuse, les travaux récents de Lucia Ferretti sur la religion en milieu urbain et le débat encore tout chaud entre Louis Rousseau et René Hardy à propos des origines et du sens du «renouveau/réveil religieux» de $1840^{23}$ rappellent que l'histoire culturelle d'une société très marquée par le catholicisme est constamment confrontée à la dimension religieuse, qu'elle soit institutionnelle ou symbolique.

L'histoire culturelle a jusqu'à maintenant mis l'accent sur le milieu urbain parce qu'elle privilégie l'opinion publique exprimée dans

22. Maurice Lemire, dir., La vie littéraire au Québec (Sainte-Foy, Les Presses de l'Université Laval), 3 vol. parus; Jacques Michon, Éditeurs transatlantiques (Sherbrooke, Éditions Ex-Libris, 1991), 244 p.; Bernard Andrès, Écrire le Québec: de la contrainte à la contrariété: essai sur la constitution des lettres (Montréal, XYZ éditeur, 1990), 225 p.; les Actes du colloque Garneau paraitront bientôt.

23. Lucia Ferretti, Entre voisins: la société paroissiale en milieu urbain: Saint-PierreApôtre de Montréal (1830-1930) (Montréal, Boréal, 1992), 262 p.; René Hardy, «À propos du "réveil religieux" dans le Québec du XIX ${ }^{\mathrm{e}}$ siècle: le recours aux tribunaux entre le clergé et les fidèles (district de Trois-Rivières)», RHAF, 48,2 (automne 1994): 187-212; Louis Rousseau, «À propos du "réveil religieux" dans le Québec du XIX $\mathrm{XI}^{\mathrm{e}}$ siècle: où se loge le vrai débat?», $R H A F$, 49,2 (automne 1995): 223-245; sur le «quasi-couple» culture-religion au Québec, voir Michel Lagrée, «Histoire religieuse, histoire culturelle», dans J.-P. Rioux et J.-F. Sirinelli, dir., op. cit., 387. 
les institutions et dans les médias de culture. Cette conjoncture historiographique ne peut faire oublier que le Québec francophone fut une société à majorité rurale «officiellement» jusqu'au recensement de 1921 et que la science québécoise eut, pendant un certain temps, une fierté: celle des enquêtes et des Archives de folklore de l'Université Laval sur la culture populaire rurale. Que reste-t-il de tout cela scientifiquement et sur le plan de la recherche active? Gérard Bouchard et l'équipe de l'Institut interuniversitaire de recherches sur les populations [IREP] renouent avec la culture populaire paysanne en récusant l'ancienne orientation idéologique des Archives de folklore, d'une part, et en étudiant, d'autre part, les rituels reliés à la naissance et au mariage dans une perspective d'analyse différentielle des comportements ethnologiques dans les «sociétés neuves» des Amériques et en France $^{24}$.

Une passerelle existe entre l'histoire culturelle et l'histoire de l'art qui n'a malheureusement pas été beaucoup empruntée par les historiens «patentés». Ce pont traverse même les siècles comme en témoignent les travaux de François-Marc Gagnon - et de littéraires comme André-G. Bourassa et Gilles Lapointe - sur la signification culturelle et intellectuelle de Borduas et de l'automatisme, ceux d'Esther Trépanier sur la modernité ou ceux d'Hervé Gagnon sur l'histoire des musées au Québec au XIX ${ }^{\mathrm{e}}$ siècle $^{25}$. La percée autour de Borduas et du Refus global fut vraiment celle d'historiens de l'art ou de la littérature.

\section{QUESTIONS DÉBATTUES}

$\mathrm{Si}$, en histoire culturelle, l'on a débattu certaines questions communes à d'autres domaines de l'histoire, on peut aussi se demander comment cette histoire culturelle a interpellé la pratique historienne québécoise dans son ensemble et comment elle a réagi aux débats de société.

24. Gérard Bouchard, «L'ethnographie au secours de la nation. Mobilisation de la culture populaire par les lettrés canadiens-français (1850-1900)», dans Simon Langlois, dir., Identités et cultures nationales. L'Amérique française en mutation (Sainte-Foy, Les Presses de l'Université Laval, 1995), 17-47; Gérard Bouchard et Martine Segalen, dir., Dynamiques culturelles interrégionales au Québec et en France (Chicoutimi, IREP, 1995), 260 p.

25. François-Marc Gagnon, Paul-Émile Borduas. Biographie critique et analyse de l' auvre (Montréal, Fides, 1978), xv-560 p.; Paul-Émile Borduas, Écrits I, édition critique par André-G. Bourassa, Jean Fisette et Gilles Lapointe (Montréal, Les Presses de l'Université de Montréal, 1987), 700 p. et Écrits II (Montréal, Les Presses de l'Université de Montréal, 1996), 2 vol.; Gilles Lapointe, L'envol des signes. Borduas et ses lettres (Montréal, CETUQ-Fides, 1996), 272 p.; Henri Gagnon, «Les musées accessibles au public à Montréal au XIX ${ }^{\mathrm{e}}$ siècle. Capitalisme culturel et idéal national», Historical Reflections/Réflexions historiques, 22,2 (1996): 351-387. 
Il est symptomatique que l'histoire culturelle ait été tenue absente de l'article et du débat sur le «révisionnisme» de la recherche historique québécoise du dernier quart de siècle. La chose est d'autant plus paradoxale que l'essentiel de ce débat porte sur la réalité et la perception de la modernité, plus ou moins consciemment réduite à la modernisation sociale, économique et technologique, évacuant du coup la question de savoir si, comment et quand cette modernité, comme référence culturelle, a afflué à la conscience individuelle et collective. Comment peut-on, par exemple, dire quoi que ce soit d'un peu définitif sur la société québécoise «normale» eu égard à son laïcisme (par opposition au «retard» religieux et clérical) ou à son cosmopolitisme (par opposition aux conflits ethniques) sans introduire les historiens du culturel et du religieux dans le débat? En un sens, cette évacuationabsence de l'histoire culturelle ne surprend pas: le débat sur le «révisionnisme» exclut la dimension culturelle et intellectuelle parce que, pour les tenants d'une évolution «normale» ou d'une «modernité» hâtive, il eut été plus difficile d'asseoir leur analyse ou leur vision en tenant un compte plus serré du destin de l'ultramontanisme et du libéralisme au $\mathrm{XX}^{\mathrm{e}}$ siècle, du conservatisme et de ses variantes idéologiques durant le premier tiers du présent siècle ${ }^{26}$. Quant aux synthèses d'histoire du Québec, elles accusent le plus souvent un retard sinon un refus du culturel, limitant celui-ci à l'histoire des idéologies, de la littérature ou de l'art.

L'apport savant et civique de l'histoire culturelle à propos de la définition et de la présence du libéralisme dans l'histoire du Québec est par ailleurs évident. Les études sur le libéralisme durant la période de l'Union en particulier et durant la période pré et postconfédérative (Sylvain, Bernard, Lamonde) ont tiré au clair les aspects doctrinaux et politiques de ce courant d'idées dont les dimensions antérieures à l'Union (1760-1837) avaient été mises en place par Claude Galarneau, Fernand Ouellet, Jean-Pierre Wallot et Pierre Tousignant ${ }^{27}$. Le chaînon manquant viendra, à propos de 1837 et de 1838 , avec les recherches de Jean-Paul Bernard. L'étude du libéralisme fin de siècle dans les milieux d'affaires francophones de Montréal a pris avec Fernande Roy une orientation originale qui invite à arrimer aux aspects doctrinaux du libéralisme (libertés, anticléricalisme) sa composante économique (laisser-faire) et sa dimension individualiste (propriété). Les aspects

26. Sur la table ronde débattant du «révisionnisme», Bulletin d'histoire politique, 3,2 (hiver 1995): 7-74.

27. On regrette la non-publication de la thèse de Pierre Tousignant, La genèse et l'avénement de la Constitution de 1791, thèse de doctorat (histoire), Université de Montréal, 1971, $496 \mathrm{p}$. 
plus doctrinaux du libéralisme sont analysés dans le collectif Combats libéraux au tournant du siècle et dans la biographie de Godfroy Langlois par Patrice Dutil. La trame du libéralisme économique et de ses composantes sociales a été récemment reprise par deux sociologues, Jules Duchastel et Gilles Bourque, et appliquée au duplessisme, contemporain du renouveau de la trame doctrinale du libéralisme chez le père Georges-Henri Lévesque et dans Cité libre $e^{28}$. Toutes les questions ayant trait aux rapports entre libéralisme «doctrinal» et libéralisme économique ne sont certes pas résolues, mais la trajectoire est tracée sur deux siècles et le débat est bien focalisé.

Les travaux sur le libéralisme et sur l'ultramontanisme ont, en un sens, entretenu le feu d'une histoire politique décriée, en transformant celle-ci d'une histoire événementielle des politiciens et des partis en une histoire des idées, du pouvoir social, des idéologies. Les recherches sur le bicentenaire du parlementarisme ou sur les insurrections ${ }^{29}$ attisaient aussi les cendres du politique. Mais c'est plutôt l'esprit du temps présent - la signification de la Révolution tranquille, du nationalisme et de l'immigration relue à la lumière du néo-libéralisme ou d'un possible «postmodernisme» - qui a facilité un certain «retour» du politique, du polémique et de l'histoire politique. Car la phase de l'analyse des idéologies indique bien que l'histoire politique n'était pas disparue de la recherche historique. Les débats autour de la «croix gammée» de l'éphémère lieutenant-gouverneur Jean-Louis Roux, autour des archives de Robert Rumilly, autour de l'affaire de Bernonville, autour du livre d'Esther Delisle sur Lionel Groulx et l'antisémitisme canadien-français ou la polémique entre Marc Angenot et Jacques Pelletier ont fait voir sinon un certain malaise intellectuel du milieu québécois francophone, du moins un manque flagrant de connaissance historique sur cette période qui va de $L^{\prime} A c$ tion française (1917-1928) au déclin des droites nationalistes des

28. Fernande Roy, Progrès, harmonie, liberté. Le libéralisme des milieux d'affaires francophones à Montréal au tournant du siècle (Montréal, Boréal, 1988), 301 p.; id., Histoire des idéologies au Québec aux XIXe et XXe siècles (Montréal, Boréal, 1993), 128 p.; Yvan Lamonde, dir., Combats libéraux au tournant du siècle (Montréal, Fides, 1995), 285 p.; Patrice Dutil, L'avocat du diable: Godfroy Langlois et la politique du libéralisme progressiste à l'époque de Laurier (Montréal, R. Davies, 1995), 286 p., traduit de l'anglais par Madeleine Hébert; Jules Duchastel et Gilles Bourque, La société libérale duplessiste (1944-1960) (Montréal, Les Presses de l'Université de Montréal, 1994), 435 p.

29. Jean-Paul Bernard, Les rébellions de 1837-1838 (Montréal, Boréal Express, 1983), 349 p. et Les rébellions de 1837 et de 1838 dans le Bas-Canada (Ottawa, Société historique du Canada, 1996), 37 p.; Allan Greer, The Patriots and the People. The Rebellion of 1837 in Rural Lower Canada (Toronto, University of Toronto Press, 1993), xiv-385 p. 
années 1950 en passant par le pétainisme et le gaullisme ${ }^{30}$. S'il est un lieu où l'histoire intellectuelle du Québec risque d'être d'un précieux apport dans les années qui viennent, c'est bien dans l'élucidation des trames idéologiques de cette première moitié du $\mathrm{XX}^{\mathrm{e}}$ siècle et dans le départage de ce qui est même, semblable et différent entre la France et le Québec, entre hier et aujourd'hui ${ }^{31}$.

En raison de sa jeunesse relative au Québec, l'histoire culturelle n'a pas eu dans ses orientations de recherche la «fantaisie» d'objets d'étude hétérogènes, de territoires marginaux, d'expériences qui peuvent paraître excentriques mais se révéler symboliquement centrales, de ce qu'Alain Corbin appelle «les cultures sensibles ${ }^{32} »$. Lorsque tout était à faire, qu'il fallait cadastrer le territoire et le temps, battre les sentiers et montrer que les chemins menaient quelque part, il était difficile de prendre un objet et de le retourner sens dessus dessous dans un vide documentaire et conceptuel. Certains historiens plus intrépides l'ont pourtant fait avec bonheur: Serge Gagnon surtout, sur la sexualité et sur la mort, André Cellard sur la folie, Jean Provencher sur les saisons ou Gilles Janson sur les sports, pour ne citer que quelques exemples ${ }^{33}$.

\section{MISE EN PERSPECTIVE NATIONALE ET INTERNATIONALE}

Pour des raisons culturelles..., l'histoire culturelle pratiquée au Québec occupe une place privilégiée dans l'historiographie canadienne. Notre initiative d'un bilan de la recherche canadienne dans le domaine de l'histoire culturelle et intellectuelle ${ }^{34}$ traduit une curiosité

30. Yves Lavertu, L'affaire Bernonville. Le Québec face à Pétain et à la Collaboration (1948-1951) (Montréal, vlb éditeur, 1994), 217 p.; Esther Delisle, Le traître et le Juif: Lionel Groulx, «le Devoir» et le délire du nationalisme d'extrême droite dans la province de Québec (1929-1939) (Outremont, l'Étincelle, 1992), 284 p.; Marc Angenot, Les idéologies du ressentiment (Montréal, XYZ éditeur, 1996), 175 p.; Jacques Pelletier, Au-delà du ressentiment. Réplique à Marc Angenot (Montréal, XYZ éditeur, 1996), 98 p.

31. Pierre Trépanier, «Notes pour une histoire des droites intellectuelles canadiennesfrançaises à travers leurs principaux représentants (1770-1970)», Cahiers des Dix, 48 (1993): 119-164.

32. Alain Corbin, «Du Limousin aux cultures sensibles», dans J.-P. Rioux et J.-F. Sirinelli, dir., op. cit., 101-115.

33. Serge Gagnon, Plaisir d'amour et crainte de Dieu. Sexualité et confession au BasCanada (Sainte-Foy, Les Presses de l'Université Laval, 1990), 202 p. et Mourir hier et aujourd'hui (Sainte-Foy, Les Presses de l'Université Laval, 1987), 172 p.; André Cellard, Histoire de la folie au Québec de 1600 à 1850: le désordre (Montréal, Boréal, 1991), 280 p.; Jean Provencher, Les quatre saisons dans la vallée du Saint-Laurent (Montréal, Boréal, 1996, $2^{\mathrm{e}}$ édition), 605 p.; Gilles Janson, Emparons-nous du sport: les Canadiens français et le sport au XIXe siècle (Montréal, Guérin, 1995), xv-239 p.

34. Journal of Canadian Studies/Revue d'études canadiennes, 24,3 (automne 1989) sur l'histoire culturelle et intellectuelle au Canada. 
et un désir scientifiques d'explorer, au-delà des clichés, les ressemblances et les différences de l'expérience culturelle des communautés anglophone et francophone.

Il est par ailleurs évident que l'histoire culturelle pratiquée au Québec trouve sa première parenté dans l'histoire culturelle française, encore qu'il ne faille point l'identifier d'emblée à «l'École des Annales» ou à ladite «Nouvelle Histoire». Tout familiers des travaux d'Ernest Labrousse, d'Alphonse Dupront, de Robert Mandrou ou de Philippe Ariès qu'aient été Fernand Ouellet, Claude Galarneau et d'autres historiens de génération différente, on peut dire que l'histoire des mentalités n'est pas un greffon qui a véritablement pris en terre québécoise, malgré la référence aux mentalités faite par Fernand Ouellet dans ses travaux et la sensibilité de Claude Galarneau à la psychologie collective, perceptible dans ses études sur la France et la Révolution devant l'opinion canadienne. Déjà au colloque de septembre 1975 sur l'histoire socioculturelle, organisé par Fernand Ouellet et Robert Mandrou - fréquemment invité à l'Université Laval -, la question du caractère opératoire de cette histoire des mentalités avait été soulevée et débattue ${ }^{35}$. Il n'en demeure pas moins que l'histoire culturelle pratiquée au Québec a hérité de l'École des Annales un sens du sériel et de la quantification, un attrait pour l'anthropologie historique, une attention à «l'outillage mental» mis en valeur par Lucien Febvre.

L'itinéraire de Claude Galarneau, qui a personnifié pendant un temps l'histoire culturelle au Québec, est révélatrice de cette influence relative de l'École des Annales: ses recherches postdoctorales ont davantage rapproché l'histoire culturelle des enquêtes lancées au début des années 1960 par François Furet sur les pratiques comme celle du livre, que des thèmes des mentalités, souvent religieux et médiévaux des Annales; on pense à ses séminaires et directions de mémoires ou de thèses sur la librairie à Québec, sur le livre dans les inventaires après décès, sur les collèges classiques ou sur l'alphabétisation, autant

35. Textes de Mandrou, Ouellet, Gagnon et Bouchard dans Histoire sociale/Social History (mai 1976): 5-28. À propos de la critique de l'histoire des mentalités, Yvan Lamonde, «La sociabilité et l'histoire socio-culturelle: le cas de Montréal (1760-1880)» (1987), Territoires de la culture québécoise, op. cit., 71-74. En plus des références qui y sont faites aux critiques français de l'histoire des mentalités, voir les positions de Daniel Roche, «Une déclinaison des Lumières» et d'Alain Croix, «Marx, la chaisière et le petit vélo», dans Pour une histoire culturelle, op. cit., 21-47 et 51-71; celle aussi d'Hubert Watelet, «Les rapports entre science et culture et les paradigmes du mouvement des Annales», dans Gérard Bouchard, dir., en collaboration avec Serge Courville, La construction d'une culture. Le Québec et l'Amérique française (SainteFoy, Les Presses de l'Université Laval, 1993), 221-250. 
d'enquêtes originales, systématiques, menées grâce à la mise au point d'appareils méthodologiques impeccables ${ }^{36}$.

Il est symptomatique aussi que les quelques historiens qui se sont attaqués aux «nouveaux objets de l'histoire» aient peu souligné, à ma connaissance, leur filiation à une «École» ou aux Annales. J'avancerais l'hypothèse qu'une histoire culturelle en construction avait d'abord besoin de lancer des enquêtes, de jeter des fondations, de poser des jalons et d'esquisser les grandes lignes des idées, des croyances et des comportements avant de permettre des analyses et des interprétations/réinterprétations à partir de terrains comme l'alimentation ou les ex-voto. Une autre façon d'identifier certaines limites à «l'audace» scientifique de l'histoire culturelle faite au Québec consiste à observer qu'on ne trouve pas ici d'équivalent thématique et méthodologique du Grand massacre des chats de Robert Darnton qui, tout en remettant en cause l'histoire des mentalités, plaidait pour un rapprochement entre l'histoire culturelle et l'anthropologie culturelle $^{37}$. Mais, faut-il le préciser, ce défi d'ouverture au symbolique est commun à toutes les pratiques nationales d'histoire culturelle.

C'est vraisemblablement parce qu'elle conjuguait la sensibilité aux mentalités des Annales et l'attention aux pratiques (Furet, Roche, Chartier) que la notion de sociabilité, élaborée et mise en pratique par Maurice Agulhon, a inspiré des historiens ${ }^{38}$. On pourrait presque dire que la proximité-distance de Maurice Agulhon à l'égard des Annales symbolise assez bien le rapport de l'histoire culturelle québécoise à cette mouvance historienne. Et parce que cette notion de sociabilité conférait sa dimension sociale au politique et qu'elle permettait sans effort suspect de retrouver la société civile dans ce politique, elle contribua à un retour acceptable du politique. Conjuguée à l'étude des élites, qui avaient eu un moment les faveurs de l'histoire sociale en France comme au Québec - pensons à la bourgeoisie des professions libérales mise au jour par Fernand Ouellet - , cette tendance de recherche allait rencontrer assez naturellement l'histoire culturelle et l'histoire intellectuelle en France et au Québec à travers l'analyse des

36. Sur l'itinéraire de Claude Galarneau, Yvan Lamonde et Gilles Gallichan, dir., L'histoire de la culture et de l'imprimé. Hommages à Claude Galarneau (Sainte-Foy, Les Presses de l'Université Laval, 1996), 11-32; Alfred Dubuc, «L'influence de l'école des Annales au Québec», RHAF, 33,3 (décembre 1979): 357-386.

37. Robert Darnton, Le grand massacre des chats. Attitudes et croyances dans l'ancienne France (Paris, Robert Laffont, 1985), 282 p.

38. Yvan Lamonde, «La sociabilité et l'histoire socio-culturelle: le cas de Montréal (1760-1880)», dans Territoires de la culture québécoise, op. cit., 71-103. 
élites intellectuelles et de l'une de leurs composantes: les intellectuels ${ }^{39}$.

Si la parenté du premier degré de l'histoire culturelle québécoise se trouve dans l'historiographie française, celle du deuxième degré peut être retracée dans l'historiographie étatsunienne. Il s'agit moins ici «d'Amérique française» au sens où l'entendait l'abbé Groulx, de vaste empire français en Amérique, que de francophones vivant en Amérique, en acceptant les conséquences et tirant, de façon critique, les conclusions culturelles et politiques de cette situation. Les références aux études et aux méthodes étatsuniennes sont désormais assez nombreuses pour que l'on puisse voir se dessiner une tendance nouvelle de l'histoire culturelle québécoise. Les travaux de Lamonde sur les associations volontaires, les bibliothèques ou la culture urbaine, ceux de Jean de Bonville sur l'histoire de la presse, ceux de Raymond Montpetit sur l'art et le spectacle urbains, ceux de Gérard Bouchard sur le monde rural, ceux de Louis Rousseau sur le «réveil religieux» de 1840 constituent autant de signes de cette tendance à considérer le développement culturel du Québec comme se faisant dans le Nouveau Monde et avec les particularités que cela implique.

On terminera par un souhait: dans cette «société neuve» du Nouveau Monde qu'est le Québec, l'histoire culturelle n'a pas bénéficié des apports des médiévistes et des historiens québécois de la Renaissance, des $\mathrm{XVII}^{\mathrm{e}}$ et $\mathrm{XVIII}{ }^{\mathrm{e}}$ siècles (Lusignan, Boglioni, Hébert, de Bujanda, Dolan) travaillant sur la culture et dont les méthodes, les questionnements et les pratiques pourraient constituer un apport stimulant, en particulier pour l'analyse de la culture en Nouvelle-France dont le dernier bilan d'Antoine Roy (Les lettres, les sciences et les arts sous le Régime français) date de 1930.

39. J.-F. Sirinelli, «Les élites...», dans J.-P. Rioux et J.-F. Sirinelli, dir., op. cit., 275-296; Yvan Lamonde, «Les "intellectuels" québécois francophones au Québec au XIX" siècle: questions préalables», RHAF, 48,2 (automne 1994): 153-185; ajoutons l'étude de Catherine Pomeyrols, Les intellectuels québécois: formation et engagements (1919-1939) (Paris/Montréal, L'Harmattan, 1996), 537 p., celle d'Alain Lacombe sur Errol Bouchette, un intellectuel (Montréal, Fides, 1997), 236 p., le numéro spécial du Bulletin d'histoire politique, 3,1 (automne 1994), les contributions de Yvan Lamonde, «Des intellectuels francophones en Amérique», et de Catherine Pomeyrols, «Histoire comparée des intellectuels: le cas du Québec», dans MarieChristine Granjon, Nicole Racine et Michel Trebitsch, dir., Histoire comparée des intellectuels (Paris, CNRS/Institut d'histoire du temps présent, 1997), 179-184 et 197-208, et le colloque de l'UQTR (mars 1997) sur «L'inscription sociale de l'intellectuel» dont les Actes paraîtront bientôt. 